\title{
Supporting Learners Within a Secondary School Context Using the My FRIENDS Youth Skills for Life Programme: Five Participants and Their Experience
}

\author{
Jeanne Currie
}

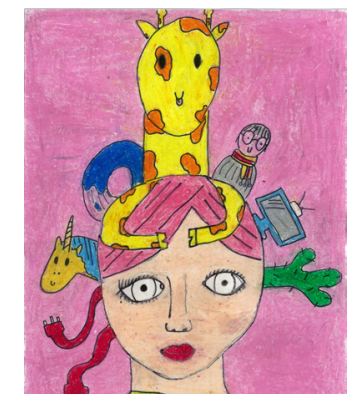

\begin{abstract}
The My FRIENDS Youth Skills for Life programme is a group cognitive behaviour therapy (CBT) based programme and was used with a group of five young secondary students who had previously experienced difficulty with emotional regulation, peer relationships and discipline at school. A mixed method approach was used and included screening questionnaires, school record data and participant feedback. Themes identified include emotional regulation, peer relationships, discipline, and classroom referrals. The mean result for emotional regulation did not reveal substantial change, however, on an individual level, one participant improved and one reduced. Peer relationships demonstrated an overall improvement. Discipline and classroom referrals reduced and the participant's recognitions (acknowledgements) increased at school. The results of the research project indicate that the My FRIENDS Youth Skills for Life programme assisted participants with developing life management skills, namely emotional regulation, developing peer and teacher relationships, and problem-solving.
\end{abstract}

\section{Research Paper}

\section{Keywords:}

emotional regulation, My FRIENDS Youth, peer relationships

\section{INTRODUCTION}

Students exhibiting emotional and behaviour difficulties have a wide variety of behavioural and mental health needs. These needs may present as anxiety, low mood, experiencing difficulty with concentration, and reduced school and classroom engagement (Schoenfield \& Mathur, 2009). Research has shown that anxiety disorders are among the most common psychiatric disorders in childhood and adolescence (Rodgers \& Dunsmuir, 2013). According to an article written by Farrell and Barrett (2005), one in six children in Australia experience clinical levels of anxiety at any given time. In New Zealand, the Ministry of Health report that more than 15,000 children were diagnosed with anxiety, which increased from 2800 children five years ago (Hill, 2013). Although children and adolescents experience episodes of anxiety as part of their typical development, for some these feelings may intensify and significantly impact their everyday activity, peer and family relationships, and academic work (Farrell \& Barrett, 2005). Some adolescents experience difficulties with low self-esteem and there is a link between selfperception and social behaviour (Barrett, Webster \& Wallis, 1999). Adolescents may have developed the appropriate skills for peer interaction, however their self-perception may cause a barrier for this interaction to occur effectively (Barrett et al.), the result being some adolescents develop unhelpful thinking styles about themselves and their relationships and are at risk of developing low mood or anxiety-related difficulties.

Young people at school learn through interactions with people, namely the teacher, their peers and family. The emotions that the young person may be experiencing can impede these interactions (Durlak, Weissberg, Dymnicki, Taylor \& Schellinger, 2011). Social emotional learning programmes "provide a foundation for better adjustment and academic performances reflected in more positive social behaviours, fewer conduct problems and less emotional distress" (Durlak et al.).

Group cognitive behaviour therapy (CBT) programmes can be used as an effective tool to provide young people with support as they create opportunities for peer interaction, sharing, providing feedback, modelling positive behaviours, problem-solving, and normalising the difficulties experienced by young people (Rodgers \& Dunsmuir, 2013). Research indicates that up to 70 percent of young people who have completed a CBTbased programme have reduced anxiety and therefore do not meet diagnostic criteria for anxiety disorder (Schoenfield \& Mathur, 2009).

The My FRIENDS Youth Skills for Life programme is a group CBT programme developed by Dr Paula Barrett at the Pathways Institute of Australia (Rodgers \& Dunsmuir, 2013). The word 'FRIENDS' is an acronym to assist young people with remembering the social and emotional learning skills of the My FRIENDS Youth Skills for Life programme. The following skills are taught in the FRIENDS programme: $\mathrm{F}$ - Feelings (learn to recognise and manage your feelings and also 
show empathy for other's feelings), R - Relax (quiet time and focus on the present, become more aware), I - Inner helpful thoughts (change unhelpful thinking to helpful thinking), E - Explore solutions and coping step plans (learn to find solutions for problems and face challenges), $\mathrm{N}$ - Now reward yourself (you have tried your best and therefore can reward yourself), D - Do it every day (practise the skills each day), S - Stay strong inside (share your skills with your family and community as they are the support groups).
This is a 10 week structured programme consisting of three components based on CBT principles: learning and behaviour; cognitive, and physiological development (Rodgers \& Dunsmuir, 2013). The learning and behaviour component involves demonstrating coping step plans and problem-solving techniques to create solutions. The cognitive component encourages young people to use positive self-talk and to start challenging the unhelpful thoughts, changing them into positive realistic thoughts. The physiological component strives to create awareness with body clues and uses relaxation techniques to foster self-regulation. Table 1 outlines the objectives and desired outcomes for the programme.

Table 1

Objectives and Outcomes of the My FRIENDS Youth Skills for Life Programme (Barrett, 2012)

\begin{tabular}{|c|c|c|}
\hline & Objectives & Outcomes \\
\hline Session 1 & $\begin{array}{l}\text { Introduce participants to each other } \\
\text { and discuss the rationale and outcomes } \\
\text { of the programme. }\end{array}$ & $\begin{array}{l}\text { The skills taught in this programme are life skills. } \\
\text { Understand that people are different and to learn to tolerate and empathise } \\
\text { with others. } \\
\text { Personal goals from each participant are set. The Te Whare Tapa Wha model } \\
\text { (Changing Minds, 2014). }\end{array}$ \\
\hline Session 2 & $\begin{array}{l}\text { Discuss the first letter of the FRIENDS } \\
\text { acronym, F - feelings. }\end{array}$ & $\begin{array}{l}\text { Develop physiological awareness; participants become aware of their bodies } \\
\text { and emotions when they feel a certain way. For example, happy, sad or angry. } \\
\text { Gain awareness of verbal and non- verbal communication. } \\
\text { Develop further empathy for others. }\end{array}$ \\
\hline Session 3 & $\begin{array}{l}\text { The focus is on developing confidence } \\
\text { and friendship skills. }\end{array}$ & $\begin{array}{l}\text { Gain an understanding about what confidence is and how they can build their } \\
\text { own confidence. } \\
\text { Reflect on the qualities in friendships. }\end{array}$ \\
\hline Session 4 & $\begin{array}{l}\text { The next letter of the FRIENDS } \\
\text { acronym is } \mathrm{R} \text { - Relaxation. }\end{array}$ & $\begin{array}{l}\text { Recognise that relaxation and mindfulness are effective methods of becoming } \\
\text { more aware of themselves and others. } \\
\text { Recognise that relaxation is another method used to work through emotions } \\
\text { that cause distress. }\end{array}$ \\
\hline Session 5 & $\begin{array}{l}\text { Using the FRIENDS acronym the ' } \mathrm{I} \text { ' is } \\
\text { used next; inner helpful thoughts. This } \\
\text { is an introduction to attention training. }\end{array}$ & $\begin{array}{l}\text { Understand the concept of positive attention and self-talk. } \\
\text { Become aware of inner thoughts and that there are different ways to think } \\
\text { about the same situation and some ways of thinking about a situation are more } \\
\text { helpful than others. } \\
\text { Introduce the group to the CBT Skateboard model. Each wheel has a theme } \\
\text { e.g. feelings, thoughts, physical reaction and behaviours. These influence each } \\
\text { other and ways to improve these are explored. }\end{array}$ \\
\hline Session 6 & $\begin{array}{l}\text { Continue with ' } \mathrm{I} \text { ' inner helpful } \\
\text { thoughts. }\end{array}$ & $\begin{array}{l}\text { Further understanding of the positive self-talk concept. } \\
\text { Continue challenging young people to think about situations that are } \\
\text { distressing in a way that may be helpful. }\end{array}$ \\
\hline Session 7 & $\begin{array}{l}\text { The 'E' explores solutions and step } \\
\text { plans. }\end{array}$ & $\begin{array}{l}\text { Learn how to set realistic goals for their problems. } \\
\text { Learn how to break down the problem into smaller, manageable steps. }\end{array}$ \\
\hline Session 8 & $\begin{array}{l}\text { Continue with the letter ' } \mathrm{E} \text { ' and } \\
\text { exploring solutions. }\end{array}$ & $\begin{array}{l}\text { Continue exploring solutions and using coping step plans. } \\
\text { Problem-solve situations using the step plan. } \\
\text { Understand and identify the importance of social support teams. }\end{array}$ \\
\hline Session 9 & $\begin{array}{l}\text { Continue exploring solutions to solve } \\
\text { problems and discuss the ' } \mathrm{N}^{\prime}-\text { Now } \\
\text { reward yourself. Discuss challenging } \\
\text { situations and how remaining calm } \\
\text { could be used to solve problems. }\end{array}$ & $\begin{array}{l}\text { Learn peace-making skills to reduce conflict and build better relationships. } \\
\text { Understand how communication can benefit conflict resolution. } \\
\text { Understand the concept of self-reward. }\end{array}$ \\
\hline Session 10 & $\begin{array}{l}\text { The final letters 'D' and 'S' include: Do } \\
\text { it every day and Stay strong inside. }\end{array}$ & $\begin{array}{l}\text { Practise and continually implement the FRIENDS skills. } \\
\text { Understand that sharing their skills with family and the community is on-going } \\
\text { and enriches everyone's lives. } \\
\text { Understand that helping others can make them feel good about themselves. }\end{array}$ \\
\hline
\end{tabular}


Studies have shown that this programme reduces anxiety both at course completion and at longer-term follow up. The FRIENDS programmes include: Fun Friends, Friends for Life, and My Friends Youth Skills for Life which are school-based anxiety prevention and resilience-building programmes developed by $\mathrm{Dr}$ Paula Barrett. The World Health Organisation (WHO) cites 'Friends for Life' as the only evidence-based programme for anxiety in children that is effective at all levels of intervention (WHO, 2004).

The Intern Psychologist (IP) trained in facilitating this programme provided the preventative programme as an option of support and intervention to the school for students with mild to moderate emotional and behavioural concerns, considered at-risk of developing more significant mental health or behavioural difficulties. The My FRIENDS Youth Skills for Life programme was used to determine the effectiveness of this programme in a New Zealand high school.

\section{METHODOLOGY}

\section{Design}

The My FRIENDS Youth Skills for Life programme is a 10-week CBT-based programme which consists of objectives outlined at the start of each session. A trained facilitator conducts the session; in the case of this group, the IP facilitated the programme. It is recommended that group sessions are conducted one to two times per week over half an hour or hourly sessions (Barrett, 2012). In the case of this group, one hour sessions were held weekly. The objective of the research project was to determine whether the My FRIENDS Youth Skills for Life programme is an effective group intervention for adolescents in a New Zealand high school.

\section{Participants}

The school was invited to select six to eight participants for this group and a total of six participants were referred. One participant attended three sessions and then withdrew from the programme. Each participant referred to the programme demonstrated various difficulties, namely: forming and maintaining positive peer relationships; emotional regulation; poor self-esteem, and behaviour difficulties at school - for example, defiance and poor teacher-student relationships.

In the first instance, students identified by the school pastoral care team to participate were informed of the programme and an informed consent form was sent home to their parents. The consent form included a section for participant consent and the option to withdraw from the programme at any stage. At the end of the programme, the facilitator discussed the possibility of using the data from the group for research submission, and outlined that their anonymity and the school's anonymity would be provided. An additional consent for research publication form was sent to the parents, and both parents and participants provided consent for this. Five participants in Year 10 (14 years old) completed the programme. The participants included four males and one female. The female reported that she felt comfortable being the only female as she has a few brothers.

The group was led by a trained facilitator of the My FRIENDS Youth for Life programme and was cofacilitated by a youth mental health practitioner. The co-facilitator was male, specifically chosen as the group consisted primarily of male participants.

\section{Data Collection}

This project used mixed-methods to measure the effectiveness of the My FRIENDS Youth for Life programme. The qualitative component of the research project included facilitator observations of participants throughout the programme as well as participant and teacher feedback at the end of the programme. Quantitative baseline and post-screening measures were used as comparative data, and the school records based on referral data and student recognitions were reviewed.

The feedback form asked participants to rate some questions from one to ten and some questions asked for YES or NO responses and comments (see Appendix One for feedback form). The teacher feedback asked the teacher to reflect on each objective of the FRIENDS acronym pertaining to one participant, noting any observed change or continued difficulties.

Two screening measures were used with participants pre- and post-programme. The Strengths and Difficulties Questionnaire (SDQ) was used as it is a brief measure for three to 16-year-olds which can be completed by parents, teachers or youths. This measure includes five self-report scales, namely: Emotional Symptoms Scale; Conduct Problem Scale; Hyperactivity Scale; Peer Problems Scale, and the Pro-Social Scale (Goodman \& Goodman, 2010). The second measure includes the Outcomes Rating Scale (ORS). A preliminary study of the reliability, validity and feasibility of the ORS conducted by Miller, Duncan, Brown, Sparks and Claud (2003) reported "the ORS was designed for use by clinicians to assess change in clients following psychological intervention. Although a short measure cannot be expected to achieve the same precision or depth of information as a longer measure like the SOQ-45.2, this study found that the ORS has adequate validity, solid reliability, and high feasibility (Miller, Duncan, Brown, Sparks \& Claud, 2003). The participants completed the SDQ and ORS individually. 


\section{Data Analysis}

Themes were outlined from qualitative anecdotal data as well as quantitative data throughout the programme to monitor the participants' progress. Qualitative and quantitative baseline and post-programme data were compared which included participants' feedback forms; school records pertaining to discipline, class referrals, and recognitions (acknowledgements or rewards). The school record data included baseline, during and post-programme data using the school data system. Two students were interviewed individually and the teachers completed feedback of the participants' progress. The feedback from teachers related to peer interactions, engagement with learning, and students following school rules. Themes relating to data sources included 'emotional regulation', 'peer relationships', and 'discipline and classroom referrals'.

\section{RESULTS AND DISCUSSION}

As a frame of reference, Table 2 and 3 have been included as a brief explanation of the SDQ and ORS scores:

Table 2

Description of SDQ Scores

\begin{tabular}{|l|c|c|c|}
\hline Scales & Normal & Borderline & Abnormal \\
\hline $\begin{array}{l}\text { Total Difficulties } \\
\text { Score }\end{array}$ & $0-15$ & $16-19$ & $20-40$ \\
\hline $\begin{array}{l}\text { Emotional Symptoms } \\
\text { Score }\end{array}$ & $0-5$ & 6 & $7-10$ \\
\hline $\begin{array}{l}\text { Conduct Problems } \\
\text { Score }\end{array}$ & $0-3$ & 4 & $5-10$ \\
\hline Hyperactivity Score & $0-5$ & 6 & $7-10$ \\
\hline Peer Problems Score & $0-3$ & $4-5$ & $6-10$ \\
\hline $\begin{array}{l}\text { Pro-Social Behaviour } \\
\text { Score }\end{array}$ & $6-10$ & 5 & $0-4$ \\
\hline
\end{tabular}

Table 3

Description of ORS Scores

\begin{tabular}{|l|c|}
\hline Scales & $\begin{array}{c}\text { Total (scores closer to 10 } \\
\text { indicate improvement). }\end{array}$ \\
\hline Individually & 10 \\
\hline Interpersonally & 10 \\
\hline Socially & 10 \\
\hline Overall & 10 \\
\hline Total & 40 \\
\hline
\end{tabular}

The following dimensions emerged as the data was collated and analysed:

\section{Emotion Regulation}

Emotion regulation includes becoming aware of one's emotions and being able to manage and modify them accordingly. Emotion regulation skills develop over the course of infancy and childhood, and continue to mature during adolescence. These skills are critical to mental health, academic achievement and good social relationships (Broderick, 2015).

Table 4

Baseline and Post-Programme Scores

\begin{tabular}{|l|c|c|}
\hline & $\begin{array}{c}\text { SDQ (total } \\
\text { difficulties score) }\end{array}$ & ORS (Total score) \\
\hline $\begin{array}{l}\text { Baseline number of } \\
\text { participants }(\mathrm{n}=)\end{array}$ & $\begin{array}{c}5 \text { (3 completed } \\
\text { the questionnaire) }\end{array}$ & $\begin{array}{c}5 \text { (2 completed } \\
\text { the questionnaire) }\end{array}$ \\
\hline Baseline scores mean & 16.3 & 29.4 \\
\hline $\begin{array}{l}\text { Post-number of } \\
\text { participant }(\mathrm{n}=)\end{array}$ & $\begin{array}{c}5 \text { (4 completed } \\
\text { the questionnaire) }\end{array}$ & $\begin{array}{c}5 \text { (4 completed } \\
\text { the questionnaire) }\end{array}$ \\
\hline Post-scores mean & 16.25 & 29.65 \\
\hline
\end{tabular}

Five participants were selected for this programme. At baseline, three SDQ questionnaires were completed and two ORS. Four SDQ and ORS questionnaires were completed post- programme.

Table 5

SDQ Total Difficulties Baseline and Post-Programme Based on Two Participants

\begin{tabular}{|l|c|c|}
\hline & $\begin{array}{c}\text { SDQ total } \\
\text { difficulties } \\
\text { baseline score }\end{array}$ & $\begin{array}{c}\text { SDQ } \\
\text { post-programme } \\
\text { score }\end{array}$ \\
\hline Participant A & $\begin{array}{c}19 \text { borderline } \\
\text { range }\end{array}$ & $\begin{array}{c}20 \text { abnormal } \\
\text { range }\end{array}$ \\
\hline Participant B & 15 normal range & 14 normal range \\
\hline
\end{tabular}

Table 6

SDQ Total Difficulties Baseline and Post-Programme Based on Two Participants

\begin{tabular}{|l|c|c|}
\hline & $\begin{array}{c}\text { ORS } \\
\text { baseline score }\end{array}$ & $\begin{array}{c}\text { ORS } \\
\text { post-programme } \\
\text { score }\end{array}$ \\
\hline Participant A & $29.5 / 40$ & $29.3 / 40$ \\
\hline Participant B & $17.4 / 40$ & $38 / 40$ \\
\hline
\end{tabular}

Participant $\mathrm{A}^{\prime}$ s baseline score indicated that his total difficulties post-programme increased by one point, demonstrating that Participant A continues to experience difficulties. After reviewing Participant A's SDQ questionnaire at baseline, the 'Emotional Symptoms Scale' and the 'Conduct Problems Scale' were both in the normal range, and post-programme these scores revealed they were both in the borderline range. Participant B's baseline SDQ score decreased by one point, indicating a slight improvement. Participant B's 'Emotional Symptoms' at baseline and post-programme was in the normal range and 'Conduct Problems' remained in the 
borderline range. The scores may increase as the participants develop awareness and insight into how they feel and respond to situations. Participants were able to become more self-reflective and honest, and therefore, for Participant $A$, the scores have increased slightly and Participant B's score indicates a slight decrease.

Participants were invited to complete a feedback form and comment on the following:

Name and make a comment on two things that you thought was good about this programme.

Participant B wrote: "The skateboard, it will help me to calm myself and mindfulness".

Another participant wrote: "I think the most helpful thing for me is learning how to deal with problems better".

During the group sessions, the participants were invited to reflect on what skills they used during the programme. Some participants reported that breathing and having some time alone was helpful, and others identified exercise as a calming strategy. This indicated that participants started developing self-reflection and awareness of their body cues as well as strategies to support them when required.

The ORS score for Participant A remained the same, however Participant B's ORS post-score demonstrated a vast improvement in his overall score.

A larger group size and the inclusion of all baseline data may have yielded better results for research purposes. A further limitation to consider is that the participants completed self-report questionnaires and therefore accuracy relies on their assessment of themselves and a trusting relationship with the facilitators. As the participants' rapport with the facilitators and group members developed throughout the programme, they were able to share openly and honestly. This will be discussed further in the next section.

\section{Peer Relationships}

During the first session of this programme, the facilitator observed that the group members experienced conflict with each other. One participant reported that he did not want to attend this group and another antagonised a particular participant during the first three sessions. During Session Three, the group interacted more and contributed to the discussion. Participants who did not share previously, started talking about being confident, and the difference between being confident and arrogant was discussed, and how being arrogant can prevent relationships from forming.

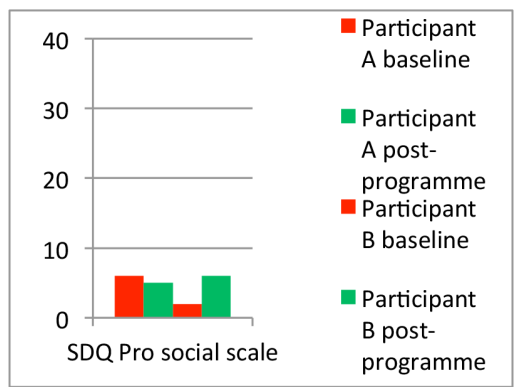

Figure 1.SDQ

Pro-Social Scale.

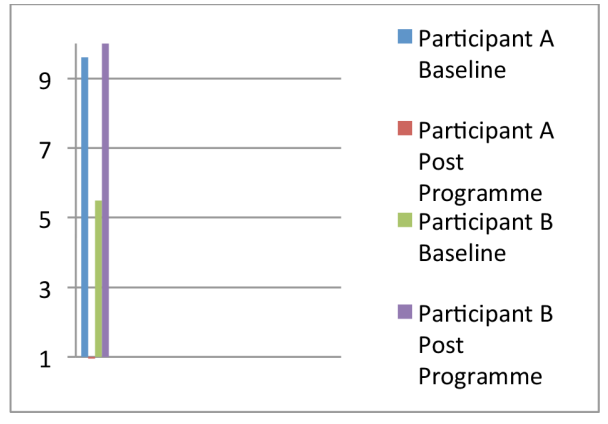

Figure 2. ORS Social Scale.

The SDQ Pro-Social mean score post-programme indicated an improvement with Participant B's score. Participant A scored within the normal range at baseline and within the abnormal range at posttesting. One other participant's score remained the same within the abnormal range and the other two participants scores have been excluded from this as they did not complete baseline data. The ORS Social Scale mean score indicated a slight reduction. This may be due to Participant A's self-reflective evaluation. During the second half of the sessions, Participant A was asked by another participant if he had depression, at which stage Participant A said "Yes". The group acknowledged Participant A for sharing this with them, and this question provided an avenue for further exploration on empathy, problemsolving, peer relationships and support networks. It is important to note that Participant A was disliked and misunderstood by some of his peers in this group, and that adolescents use the word 'depression' colloquially at times rather than in the clinical sense. During Session Eight, we continued the discussion on exploring solutions and increasing support networks. During this session, Participant A revealed that he used to be bullied by some of the participants in the group and this had stopped. One participant in particular had said that they did not have to be "mates", but they can respect and acknowledge each other. Participant B was another group member who did not like Participant A and reported, "I'II have your back if anyone bullies you". Participant A's physical education (PE) teacher reported the following feedback post-programme:

"I would like to add that Participant $B$ and Participant $A$ 's relationship seems to be stronger and has been positive in PE". 
"Participant A has been less edgy in PE. Working well in his group".

The mathematics teacher provided feedback on one participant in the group for I = I can do it (challenging negative thoughts and developing more confidence):

"Participant $X$ can be quite positive towards work and asks questions willingly".

The graph and feedback from teachers, as well as the peer discussions in the group, indicates that the My FRIENDS Youth Skills for Life programme provides an opportunity for improved peer relationships and support networks. A six week follow-up period on this group may provide further evidence of the sustainability of peer relationships and support networks.

\section{DISCIPLINE AND CLASSROOM REFERRALS}

The school where this programme was facilitated has a classroom referral system whereby students are referred out-of-class for breaking the school rules. An example of some of the referrals that the participants in the group may have been sent to the Head of House for include not listening to instructions, for example: not removing headphones; students must remove their jacket in class; not settling/sitting at the table as the lesson starts; wearing the incorrect uniform. Discipline includes occurrences where the participants' parents may have been consulted or have attended a meeting to discuss their son/ daughter's continued lack of discipline. Recognitions are acknowledgments or rewards that students receive from the school. The school uses FAITH cards to reward students as it is a catholic school. For example, if a student is respectful, they receive a FAITH card called 'Respect'.

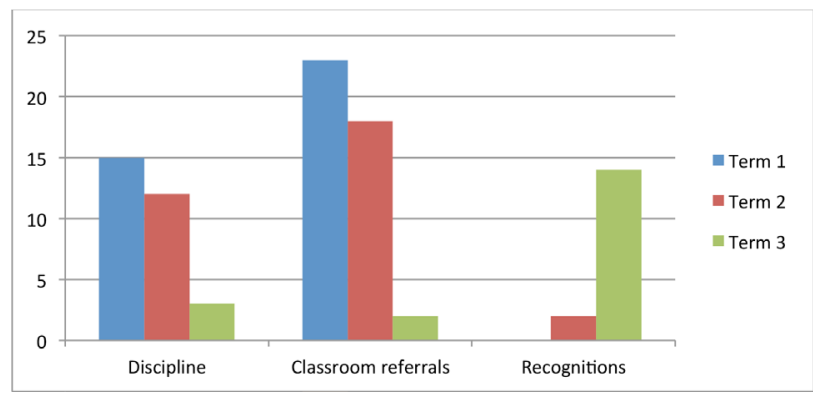

Figure 3. Baseline, During and Post-Programme Data on Discipline, Classroom Referrals and Recognitions.

These scores are based on all five participants, derived from the school record system. A mean was calculated for each category. At baseline (Term 1 ), the graph indicates that the participants were receiving discipline and classroom referral (sent to the Head of House/Dean of the school) incidents and no recognitions. When the programme started (Term $2)$, the discipline and classroom referrals reduced slightly and recognitions started to increase. As the programme ended, the post-programme data-based at three weeks (Term 3), indicates that the discipline and classroom referrals have reduced and recognitions have increased.

During two individual interviews with participants who completed the programme they were asked how Term 3 had been going:

"I have not been sent to the Head of House this term and this term has been better than the previous terms".

The same participant rated his behaviour 3/10 (10

$=$ good) at the start of the year and 7/10 for the second part of the year.

One teacher provided feedback and reported the following:

"He has not been as disruptive, always sits in his allocated seat without question, following my procedures for entering the classroom without incident".

A teacher provided feedback on Participant B:

"He is doing really well in class, being cooperative, polite and responsive.

He is also working hard and completing all tasks given. I am really enjoying him".

The data indicates that the participants have all improved in the area of discipline and reduced classroom referrals, with an increase in recognitions. Further evidence is required to determine whether these improvements will be sustained.

\section{FRIENDS for Life Programme Outcomes}

The feedback from participants of the programme are summarised below; a mean score was calculated for each scale below:

Please indicate on a scale of one to ten (one $=$ poor and ten $=$ fantastic)

The overall My FRIENDS Youth Skills for Life programme 1

7

The facilitators were a good fit for me 1

The learning activities were thought-provoking

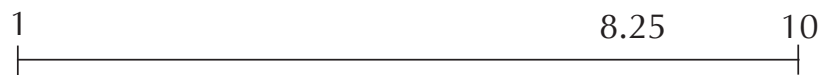

The mean scores indicate that the participants were satisfied with the My FRIENDS Youth Skills for Life programme.

The second part of the feedback form asked participants to circle YES or NO and include a brief comment. Four feedback forms were received and two participants circled YES to all the questions in that section and 
one participant indicated the programme helped her become more social. Another participant highlighted that he learnt how to calm himself.

One participant reported that he would not use the My FRIENDS skills in his life as he did not think it would work for him.

The group was asked to comment on one thing that could be improved and three people commented: "More food"; "[Participant C's] behaviour" and "Listening". The participants did not elaborate on these.

The facilitators provided rewards in the form of chocolates, and the group sometimes started before morning tea. This may indicate why food, as a comment, has been highlighted. Participant C attended five sessions as he was absent on the other days; due to reduced participation of sessions he may not have learned some of the skills by the end of the group. With the comment "Listening", it may have been more helpful if the facilitators met individually with each participant, and once they completed the feedback form some clarifying questions could have been asked. Two participants reported that they would recommend this programme to their friends, one said "Maybe" and the other said "No. He would not like it".

\section{CONCLUSION}

The aim of this project was to determine the effectiveness of the My FRIENDS Youth Skills for Life programme in a New Zealand high school. Five 14-year-old participants in a New Zealand secondary school completed the programme: four males and one female. Participants who were referred experienced difficulties with forming and maintaining positive peer relationships; emotional regulation; poor self-esteem, and behaviour difficulties at school: for example, defiance and poor teacher-student relationships. The My FRIENDS Youth Skills for Life programme develops life skills that assist adolescents in effectively coping with challenging situations; furthermore, it encourages peer learning and promotes positive relationships.

The Emotional Regulation overall SDQ and ORS mean averages did not reveal substantial changes; on an individual scale between two participants, one participant improved and the other reduced. These results may be due to the participants developing further self-awareness. A larger sample size with baseline data would be required for future study.

This group demonstrated that it assists in developing and improving peer relationships. A six-week followup period on this group may provide further evidence if peer relationships and support networks are sustained. A similar recommendation is required for the 'Discipline and Classroom' referral data, although there has been a marked improvement. Further postprogramme data may reveal how effective this group is at sustaining the skills learnt.

Overall, the participants indicated that they were satisfied with the programme. Facilitators could consider meeting with participants individually to clarify certain questions and discuss some answers further; caution would be required to prevent directing the research. Positive pro-social changes at an individual level are evident, and, as a group, the participants 'Discipline, Classroom Referral and Recognition data' indicate improvements. This research project indicates that the My FRIENDS Youth Skills for Life programme assisted participants with developing life-management skills, namely emotional regulation, developing peer and teacher relationships, and problem-solving. Research, utilising a larger sample size and collecting baseline and postprogramme data, may reflect the effectiveness of this group further.

\section{REFERENCES}

Barrett, P. (2012). My FRIENDS youth skills for life: Group Leader's Manual for Youth. Australia: Pathways Health and Research Centre.

Barrett, P., Webster, H., \& Wallis, J. (1999). Adolescent self-esteem and cognitive skills training: A schoolbased intervention. Journal of Child and Family Studies, 8(2), 217-227.

Broderick, P. (2015). Learning to breathe: A mindfulness curriculum for adolescents. Retrieved from: http://learning2breathe.org/about/purpose.

Farrell, L., \& Barrett, P. (2005). Community trial of an evidence-based anxiety intervention for children and adolescents (the FRIENDS program): A Pilot Study. Behavior Change, 22(4), 236-248.

Goodman, A., \& Goodman, R. (2010). Population mean scores predict child mental disorder rates: Validity of strengths and difficulties prevalence estimaters in Britain. Journal of Child Psychology and Psychiatry, 52(1), 100-108.

Hill, M. (2013). Number of anxious kids skyrockets. Retrieved from: http://www.stuff.co.nz/nationalhealth

Miller, S., Duncan, B., Brown, J., Sparks, J., \& Claud, D. (2003). The outcome rating scale: A preliminary study of the reliability, validity, and feasibility of a brief analog measure. Journal of Brief Therapy, 2(2), 91-100. 
Rodgers, A., \& Dunsmuir, S. (2013). A controlled evaluation of the 'FRIENDS for Life' emotional resiliency programme on overall anxiety levels, anxiety subtype levels and school adjustment. Child and Adolescent Mental Health, 20(1), 13-19.

Schoenfield, N., \& Mathur, S. (2009). Effects of cognitive-behavioral intervention on the school performance of students with emotional or behavioral disorders and anxiety. ProQuest Education Journals, 34(4,) 184.

World Health Organisation (2004). Prevention of mental disorders. Effective interventions and policy options summary report. Geneva: Author.

\section{Appendix One:}

\section{Feedback form}

Please indicate on a scale from one to ten (one $=$ poor and ten $=$ fantastic)

a. The overall My FRIENDS Youth Skills for Life programme.

b. The facilitators were a good fit for me.

c. The learning activities were thought-provoking.

Please answer YES or NO to the following and provide a brief comment:

d. Do you feel you have learned about the FRIENDS skills?

e. Would you use the FRIENDS skills in your life?

f. Has the programme taught you how to problemsolve when difficult situations arise and handle situations better?

g. Would you recommend this programme to a friend?

Please comment on the following:

h. Name and make a comment on two things that you thought was good about this programme.

i. Name and make a comment on at least one thing that could have been improved.

\section{AUTHOR PROFILE}

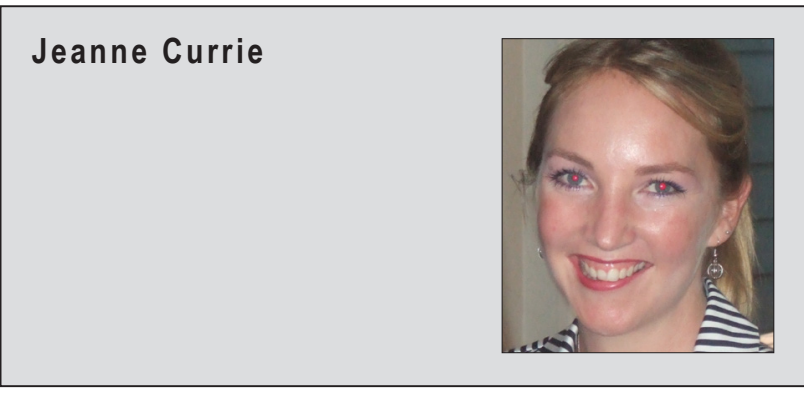

Jeanne Currie was born in South Africa and worked as a teacher in primary education for seven years. In 2011 Jeanne immigrated with her husband to New Zealand and continued studying in the field of educational psychology. Jeanne has worked with young people experiencing anxiety related difficulties in an individual and group context. Jeanne is currently completing the Post Graduate Diploma in Educational Psychology Internship at Massey University.

Email: jeannecurrie15@gmail.com 